\title{
An overview of the regulatory planning system in New South Wales: identifying points of intervention for health impact assessment and consideration of health impacts
}

\author{
Patrick J. Harris ${ }^{\mathrm{A}, \mathrm{B}}$, Ben F. Harris-Roxas ${ }^{\mathrm{A}}$ \\ and Elizabeth Harris ${ }^{\mathrm{A}}$ \\ ${ }^{\mathrm{A} C e n t r e ~ f o r ~ H e a l t h ~ E q u i t y ~ T r a i n i n g, ~ R e s e a r c h ~ \& ~ E v a l u a t i o n ~}$ \\ (CHETRE), University of New South Wales \\ ${ }^{\mathrm{B} C o r r e s p o n d i n g ~ a u t h o r . E m a i l: ~ p a t r i c k . h a r r i s @ u n s w . e d u . a u ~}$
}

\begin{abstract}
The experience of health impact assessment (HIA) in NSW has shown that it is possible to incorporate considerations of health impacts into decision-making concerning urban planning. In NSW, the Environmental Planning and Assessment Act 1979 is the regulatory framework governing urban planning. This legislative system provides opportunities for HIA and the consideration of health impacts as part of developing plans, policies and development proposals within NSW.
\end{abstract}

The benefits and promises of health impact assessment (HIA) for urban planning have been clearly articulated throughout this issue of the Bulletin and in the broader international literature. HIA can incorporate the consideration of health, the wider determinants of health and health inequity within urban planning decision-making, ${ }^{1,2}$ while providing opportunities for collaborative work between health and other sectors, including urban planning. ${ }^{3-6}$

Land-use planning and development in NSW is governed by the Environmental Planning and Assessment Act 1979. ${ }^{7}$ The Act provides opportunities for the use and development of HIA as an urban planning tool and the consideration of health impacts within the planning and development system. Table 1 outlines the objectives of the Act which have direct links to the wider determinants of health. ${ }^{3,8}$ However, this important statutory influence on health is largely unknown to health professionals.

This article provides an overview of the planning system, focussing on statutory plan-making and the development assessment process. The purpose is to provide health pro- fessionals with a summary of the complex regulatory framework which governs urban planning in NSW, suggesting points of intervention for HIA within this system. The discussion will assist health professionals to better communicate with their planning colleagues in proposing the effective use of HIA in all planning decisions - from broad plans to the determination of site-specific development applications. It encourages them to consider adverse health impacts as well as positively providing for the wellbeing of the community.

\section{The two levels of the planning system:}

\section{plan-making and development assessment}

The Act covers two principal areas of interest for HIA, plan-making and development applications. Both provide valuable opportunities to encourage consideration of health impacts and the use of HIA.

\section{Plan-making}

Plan-making is covered by Part 3 of the Act through statutory and non-statutory environmental planning instruments (Figure 1), which link directly to health and well-being through their provisions. These instruments include: protecting the environment; controlling development; reserving land for public use; the provision, maintenance and retention of affordable housing; controlling advertising; and protecting and conserving ecological communities. An additional opportunity presents itself with respect to 'such other matters as are authorised or required to be included in the environmental planning instrument by this or any other Act'. ${ }^{7}$ Accordingly, considerations under the NSW Public Health Act 1991 could be taken into account at this point.

\section{Statutory environmental planning instruments}

There are three statutory environmental planning instruments: (1) State Environmental Planning Policies, (2) Regional Environmental Plans and (3) Local Environmental Plans.

(1) The first of these, State Environmental Planning Policies, deals with issues of significance to the state and people of NSW and are overseen by the NSW State Government. There are over 70 of these, many of which have direct and indirect links to health. ${ }^{9}$ 


\section{Table 1. Objectives of the NSW Environmental Planning and Assessment Act 1979, No. 203}

The objectives of this Act are:

(a) to encourage:

(i) the proper management, development and conservation of natural and artificial resources, including agricultural land, natural areas, forests, minerals, water, cities, towns and villages for the purpose of promoting the social and economic welfare of the community and a better environment

(ii) the promotion and co-ordination of the orderly and economic use and development of land

(iii) the protection, provision and co-ordination of communication and utility services

(iv) the provision of land for public purposes

(v) the provision and co-ordination of community services and facilities

(vi) the protection of the environment, including the protection and conservation of native animals and plants, including threatened species, populations and ecological communities, and their habitats

(vii) ecologically sustainable development and

(viii) the provision and maintenance of affordable housing

(b) to promote the sharing of the responsibility for environmental planning between the different levels of government in the State and

(c) to provide increased opportunity for public involvement and participation in environmental planning and assessment.

Source: NSW Government. Environmental Planning and Assessment Act 1979 No. 203.

\begin{tabular}{|c|}
\hline \multicolumn{2}{|c|}{$\begin{array}{c}\text { Environmental Planning and } \\
\text { Assessment Act and Regulation }\end{array}$} \\
\hline Environmental Planning Instruments \\
(EPI) \\
\hline $\begin{array}{c}\text { State Environmental Planning } \\
\text { Policies eg Growth Centres, Building } \\
\text { Sustainability Index }\end{array}$ \\
\hline $\begin{array}{c}\text { Regional Environmental Plans } \\
\text { eg Sydney water catchment }\end{array}$ \\
\hline $\begin{array}{c}\text { Local Environmental Plans } \\
\text { (per local council) }\end{array}$ \\
\hline $\begin{array}{c}\text { Development control plans } \\
\text { eg guidance on safety } \\
\text { (crime prevention through } \\
\text { environmental design [CPTED]) }\end{array}$ \\
\hline
\end{tabular}

${ }^{*}$ Regional Environmental Plans are increasingly being superseded by Regional Strategies.

Source: Dr Danny Wiggins, personal communications.

Figure 1. Part 3 of the NSW Environmental Planning and Assessment Act 1979.
(2) At the next level, Regional Environmental Plans are also overseen by the NSW State Government. These plans may also incorporate health-related issues, providing detailed regional land-use planning across issues such as urban growth, commercial centres, extractive industries, recreational needs, rural lands, and heritage and conservation. ${ }^{10}$

(3) Local Environmental Plans are statutory instruments overseen by the NSW State Government but are developed and implemented by local government. They guide zoning of land use and development standards. Zoning establishes which types of land use are permitted or prohibited, eg a supermarket may be permitted in a commercial zone but not in a residential zone. Development standards control aspects of developments such as regulating the height of buildings or the amount of open space to be provided. At the time of writing, councils are revising their Local Environmental Plans using a mandated State Government standard template. ${ }^{11}$ This will provide more direct opportunities through creative interpretation of the legislation for health impacts to be incorporated at the local level.

\section{Non-statutory environmental planning guidance documents}

Local Environmental Plans are directly linked to other non-statutory (and therefore more flexible) local planmaking processes. Of specific importance to health are Development Control Plans. These plans support and supplement controls established in the Local Environmental Plans by way of more detailed planning and design guidelines that must be taken into account by a development. For example, a Local Environmental Plan will specify 
what uses are permitted through zoning (eg town houses in a residential zone). In turn the Local Environmental Plan can link to a Development Control Plan which guides the way this development is carried out and what should be in place when the development occurs (eg cycleway to encourage physical activity). ${ }^{12}$ Development Control Plans may also be related to other plans such as a 'place plan' to establish sites for community centres in a residential area which can build social capital. At the same time, Development Control Plans can link to Section 94 of the Act (Contribution towards provision or improvement of amenities or services), which requires developers to contribute additional facilities and services as a result of their development (eg the provision of public parkland).

Another important non-statutory planning document created by the State Government, and replacing Regional Environmental Plans, are Regional Strategies. While not statutory instruments, they are policy documents providing ministerial direction which Local Environmental Plans are required to follow. ${ }^{10}$ Therefore improved consideration of health impacts within Regional Strategies could have a wide-reaching influence on health and well-being (see Wells et al. in this issue).

\section{Development assessments}

Development assessments, the consideration of specific proposals for development, are covered by Part 3A and Part 4 of the Act. Part 3A is concerned with developments defined as 'Major Projects' by the Minister for Planning, and their assessment is overseen by State Government. ${ }^{13,14}$ Part 4, which relates to other developments, is managed by local government (guidance is available from each local council). For all developments in both Parts 3A and Part 4, there are three stages in the assessment process at which consideration of health, or use of HIA, can be inserted: (1) consultation before lodgement of an application; (2) the lodgement of an application; and (3) the assessment of the application.

\section{(1) Consultation before lodgement of an application}

A proponent will consult either the Department of Planning (Part 3A applications) or local government (Part 4). At this stage, there are opportunities for health to engage with both the Department of Planning and individual local councils to encourage the consideration of health at this early stage of the process. For Part 3A applications, the Department of Planning provides information that must be included in the submission of an environmental assessment. For Part 4, individual local councils provide guideline documents for lodgement requirements.

\section{(2) Lodgement of an application}

This stage, when the assessment is lodged (for both Part 3a and 4), provides further opportunities for health and wellbeing to inform the initial acceptance or rejection of the assessment by the Department of Planning or local council. For Part 3A, following consultation with relevant agencies (including the Department of Health), the Director General of the Department of Planning may request additional information or refuse to exhibit the environmental assessment. For Part 4, local councils may reject applications that are unclear in their intentions or provide insufficient information; or councils may request additional information.

\section{(3) Assessment of the application}

For Part 3A, the Director General will consult with relevant agencies before finalising an assessment report. This report is then submitted to the Minister for a determination; the project can be rejected or approved, with conditions considered appropriate.

For Part 4, local governments assess applications using criteria laid out in Section 79c of the Act. Section 79c contains many avenues of influence for health, through five considerations. The first considerations are environmental planning instruments (State Environmental Planning Policies, Regional Environmental Plans, Local Environmental Plans, Regional Strategies) and Development Control Plans. Second considerations are any potential impacts of the development, including environmental, social and economic. The third considerations involve the suitability of the site for the development (eg any natural characteristics, ease of access and availability of services). The fourth considerations entail submissions made in accordance with the Act (eg from neighbours, other bodies such as advocacy agencies). The fifth considerations encompass the public interest, including health and wellbeing.

\section{Conclusion}

This overview of the regulatory planning system in NSW provides an insight into the consideration of health and health impacts in planning. However, a word of warning is required. Despite the importance of regulation governing the work of those involved in planning, research in Australia and overseas has indicated that regulations alone are insufficient to fully address health impacts. ${ }^{15,16} \mathrm{~A}$ more strategic and creative approach is required that combines regulation with proactive strategies by the health sector to foster collaboration and trust.

\section{Acknowledgement}

We would like to thank Dr Danny Wiggins (planning and design consultant and private developer) for comments on drafts of this paper.

\section{References}

1. Frumkin H. Healthy places: exploring the evidence. Am J Public Health 2003; 93(9): 1451-6.

2. Frumkin H, Frank L, Jackson R. Urban sprawl and public health: designing, planning, and building. Washington DC: Island Press, 2004. 
3. Barton H. A health map for urban planners: towards a conceptual map for healthy, sustainable settlements. Built Environ 2005; 31(4): 339-55. doi:10.2148/benv.2005.31.4.339

4. Northridge ME, Sclar E. A joint urban planning and public health framework: contributions to health impact assessment. Am J Public Health 2003; 93(1): 118-21.

5. WHO Europe. Health impact assessment: healthy cities and urban governance, 2005. Available at http://www.euro.who.int/healthy-cities/UHT/20050201_10, accessed 22 August 2006.

6. Dannenberg AL, Bhatia R, Cole BL, Dora C, Fielding JE, Kraft $\mathrm{K}$ et al. Growing the field of health impact assessment in the United States: an agenda for research and practice. $\mathrm{Am} J$ Public Health 2006; 96: 262-70. doi:10.2105/AJPH.2005.069880

7. NSW Government. Environmental Planning and Assessment Act 1979, No. 203, 1979

8. Dahlgren G, Whitehead M. Policies and strategies to promote social equity in health. Stockholm: Institute for Future Studies, 1991.

9. NSW Department of Planning. State environmental planning policies, 2007.
10. NSW Department of Planning. Implementation of regional strategies - ministerial direction (Local Planning, Section 117 Directions). Sydney: NSW Government, NSW Department of Planning, 2007.

11. NSW Department of Planning. Local plan making, 2007.

12. National Heart Foundation of Australia. Healthy by design: a planner's guide to environments for active living. West Melbourne: National Heart Foundation of Australia (Victoria Division), 2004.

13. NSW Department of Planning. NSW major projects assessment system: a community guide. Sydney: NSW Government, 2005.

14. NSW Department of Planning. Project applications under Part 3A: steps in the process. Sydney: NSW Government, NSW Department of Planning, 2005.

15. National Public Health Partnership. Health impact assessment: legislative and administrative frameworks. Melbourne: National Public Health Partnership, 2004.

16. Banken R. Health impact assessment: how to start the process and make it last. Bull World Health Organ 2003; 81: 389-91. 